\title{
Text Comprehension as a Problem Solving Situation*
}

\section{Comprensión de textos como una situación de solución de problemas}

Recibido: diciembre 19 de 2012 | Revisado: mayo 4 de 2013 | Aceptado: junio 17 de 2013

\author{
FERNANDO MARMOLEJO-RAMOS ** \\ University of Adelaide, Adelaide, Australia \\ JAZMÍN CEVASCO *** \\ National Scientific and Technical Research Council, \\ Buenos Aires, Argentina
}

doi:10.11144/Javeriana.UPSY13-2.tcps

Para citar este artículo: Marmolejo-Ramos, F., \& Cevasco, J. (2014). Text comprehension as a problem solving situation. Universitas Psychologica, 13(2), 725-743. doi:10.11144/Javeriana.UPSY13-2. tcps

The authors would like to thank Alejandro Jiménez, Denise MacLeod, Maureen Goldfinch, and Nathaniel de Heer for assisting with proofreading this manuscript, Rosalyn Shute for the revision of the structure of this paper, and Bernoit Lemaire, Hidetsugu Komeda, and Meni Yeari for suggestions and clarifications regarding some of the ideas presented herein. We also thank Chad Habel for providing a definition of the concept "applied settings".

** Correspondence concerning this article should be addressed to Fernando Marmolejo-Ramos, School of Psychology, Faculty of Health Sciences, University of Adelaide, Adelaide, S. A., 5005, Australia. Web page: http://sites.google.com/site/ fernandomarmolejoramos/ E-mail: fernando.marmolejoramos@adelaide.edu.au

**** National Scientific and Technical Research Council (CONICET).E-mail: jazmincevasco@psi.uba.ar

\section{A B S T R A C T}

Research in text comprehension has provided details as to how text features and cognitive processes interact in order to build comprehension and generate meaning. However, there is no explicit link between the cognitive processes deployed during text comprehension and their place in higher-order cognition, as in problem solving. The purpose of this paper is to propose a cognitive model in which text comprehension is made analogous to a problem solving situation and that relies on current research on well-known cognitive processes such as inference generation, memory, and simulations. The key characteristic of the model is that it explicitly includes the formulation of questions as a component that boosts representational power. Other characteristics of the model are specified and its extensions to basic and applied research in text comprehension and higher-order cognitive processes are outlined.

Keywords

Embodied cognition, generation of inferences, narrative text, language comprehension, problem solving situation, text comprehension.

\section{RES U MEN}

La investigación en la comprensión de textos ha dado detalles de cómo las características del texto y los procesos cognitivos interactúan con el fin de consituir la comprensión y generar significado. Sin embargo, no existe un vínculo explícito entre los procesos cognitivos desplegados durante la comprensión de textos y su lugar en la cognición de orden superior, como en la resolución de problemas. El propósito de este trabajo es proponer un modelo cognitivo en el que la comprensión de textos se hace similar a una resolución de problemas y la situación que se basa en la investigación actual sobre los procesos cognitivos conocidos como la generación de la inferencia, la memoria y las simulaciones. La característica clave del modelo es que incluye explícitamente la formulación de las preguntas como un componente que aumenta la potencia de representación. Otras características del modelo se especifican y sus extensiones a la investigación básica y en la comprensión de textos y de orden superior los procesos cognitivos se describen aplican. Palabras clave

Cognición corporizada, generación de inferencias, texto narrativo, comprensión de lenguaje, situación de resolución de problemas, comprensión de textos. 
Several studies have been devoted to the comprehension of narrative texts (Bortolussi \& Dixon, 2003; Elosúa, 2000; Gerrig, 1993; Mar, 2011; Marmolejo-Ramos, Elosúa de Juan, Gygax, Madden, \& Mosquera, 2009; Suh \& Trabasso, 1993; Trabasso \& Sperry, 1985; Trabasso \& van den Broek, 1985; Trabasso, van den Broek, \& Suh, 1989; van den Broek \& Trabasso, 1986; van Dijk \& Kintsch, 1978; Zwaan, Graesser, \& Magliano, 1995). The results of these investigations have elucidated the cognitive processes that support text comprehension, and have even been extrapolated to applied settings (i.e., contexts of practice in which the research findings are relevant). For instance, it has been recommended that people with mild cognitive impairment should be provided with texts that do not demand much use of memory resources or generation of inferences, since this population performs poorly at these tasks (see, Schmitter-Edgecombe \& Creamer, 2010). However, studies that have focused on the cognitive processes involved in text comprehension seem rather isolated and unconnected with the study of high-order cognition (i.e., cognitive processes requiring imagery, ideation, abstraction, and symbolisation). For instance, the ways that the integration of multiple ideas and facts feed the simulation of events referred to in narratives has not been investigated. This gap suggests that it is pertinent to explore whether narrative text comprehension can be understood as a complex thinking process or problem-solving situation.

This article aims to propose that the comprehension of narrative texts can be understood as a problem solving situation, in that most of the cognitive processes that constitute these solving situations are also part of discourse comprehension. What is more, framing text processing as a problem solving situation can contribute to the development of comprehensive research into narrative text comprehension that has clearer extensions to applied settings. In order to make a case for this, those cognitive processes that are essential in text comprehension are identified first. Next, the role of text features in the comprehension process is discussed. Subsequently, the comprehension of narrative texts is expressed as a problem solving situation. Finally, we present a discussion of how text comprehension, seen as a problem solving task, not only has applications in educational settings, but can also inform research into higher-order cognitive processes.

\section{Cognitive Processes Involved in Narrative Text Comprehension}

Comprehension can be defined as a high-order cognitive process that involves inferential, perceptual, and encoding processes supported by memory and attention systems, and in which background knowledge and contextual factors play a key role (de Vega, 1984; van Dijk \& Kintsch, 1978; McNamara \& Magliano, 2009; Zwaan \& Rapp, 2006). However, recent advances in cognitive science and neuroscience (e.g., Mar, 2011; Siakaluk et al., 2008; Speer, Reynolds, Swallow, \& Zacks, 2009) indicate that other cognitive and neural aspects might be involved. Particularly, at the cognitive level, simulation processes should be considered and, at a neural level, neural structures and activities that support specific cognitive processes should be taken into account (see, Gallese \& Sinigaglia, 2011; Marmolejo-Ramos, 2007a, 2007b). Another topical development relates to the content of background knowledge. Recent research indicates that background knowledge is composed of sensorimotor representations acquired through direct experience with the environment (see, Marmolejo-Ramos et al., 2009). These added dimensions suggest that text comprehension can be seen as a problem solving situation.

Previous works have already addressed the role of memory and inference in text comprehension (e.g., de Vega \& Cuetos, 1999; Elosúa, 2000; Graesser, Millis, \& Zwaan, 1997; McNamara \& Magliano, 2009; van den Broek, 1990, 1994; Zwaan \& Rapp, 2006). Working memory (WM) allows for the retention of information being processed online, and long-term memory (LTM), for the recovery of previous records. In the context of discourse processing, LTM stores linguistic and world knowledge based on experience. Experience-based knowledge covers not only general knowledge of the world, but also particular memories or incidents (Graesser \& Wiemer-Hastings, 1999; Kintsch \& 
Mangalath, 2011; Tulving, 1999; Versace, Labeye, Badard, \& Rose, 2009). Also, this memory system contains information regarding reading experience in general, and experience with narrative texts in particular. Conversely, the purpose of WM (or short-term memory) is to keep a limited amount of information active for a brief period of time (Baddeley, 2010; Carreti, Borella, Cornoldi, \& de Beni, 2009; Kneepkens \& Zwaan, 1995).

In turn, the generation of inferences helps to integrate the contents of memory with the information provided by the text. That is, the generation of inferences can be defined as the activation of information not explicitly mentioned during the processing of discourse (van den Broek, 1990, 1994). Several factors influence whether inferences are generated or not: contextual support, distance between the statements that need to be connected, and individual differences (Cook, Guéraud, Was, \& O’Brien, 2007; Guéraud, Tapiero, \& O’Brien, 2008; Lassonde \& O'Brien, 2009; McNamara \& Magliano, 2009; McNamara \& McDaniel, 2004; McNamara \& O'Reilly, 2009; McNamara \& Scott, 2001; Millis, Magliano, \& Todaro, 2006; O’Brien, Cook, \& Guéraud, 2010; O’Reilly \& McNamara, 2007; Ozuru, Dempsey, \& McNamara, 2009).

Both inferential processes and memory systems (and also simulation processes) have neuronal structures that have a particular neuronal activity. Since the cognitive processes that support comprehension have neuronal support, it is currently agreed that text comprehension entails specific neurocognitive components (see, Baretta, Tomitch, MacNair, Lim, \& Waldie, 2009; Deen \& McCarthy, 2010). However, this paper seeks to highlight not the neuronal aspects of text comprehension but rather the cognitive components involved in the comprehension of narratives that help to understand text comprehension as a problem solving situation (for a review on text comprehension and its neuronal bases see, Mar, 2004, 2011; MarmolejoRamos et al., 2009). In particular, the role of simulation processes warrants attention as a core cognitive component of text comprehension.

Simulation can be defined as the construction of a dynamic mental representation of actions, perceptions, and anticipation of future events (see, Hesslow, 2002). In the case of narrative text comprehension, simulation is the mental recreation of the events referred to in the text in order to activate information about possible cognitive, affective, and bodily states of the characters and their actions (see, Marmolejo-Ramos et al., 2009). For example, Ditman, Brunyé, Mahoney, and Taylor (2010) found that readers simulate actions described in the text more easily when the pronouns used involve the reader in the narrative (e.g., "you cut the tomato" vs. "he cuts the tomato" or "I cut the tomato"). The authors argue that when readers are treated as actors in the narrative (through the use of the pronoun "you"), both the perceptual and the motor information involved are more easily retained (see also, Brunyé, Ditman, Mahoney, \& Taylor, 2011). Proof of this is that readers remember the actions described with greater precision, although they have lower performance in remembering the object of the action. These results suggest that sensorimotor representations are constructed during simulation processes not only in real action but also when they serve to explain fictional events.

Since background knowledge is dependent on sensorimotor experiences with the environment, it is logical that representations constructed during simulation processes have similar properties. Representations originating during the comprehension of narrative texts, traditionally known as situation models (see, Zwaan \& Radvansky, 1998), have hitherto not accounted for the role of sensorimotor experiences. Under a new definition, the representations originating during text comprehension can be termed embodied situation models (see, Glenberg, 1999). For example, in one experiment, Radvansky and Copeland (2010) (Experiment 1) showed that readers updated their situation models with respect to spatial changes referred to in the text. In particular, they took longer to recognize physical entities mentioned earlier in the text than those belonging to more recent events in the narrative (see also, Bower \& Morrow, 1990). Such evidence highlights the ongoing role of experience of the text environment in creating a mental model of a text. That is, the 
knowledge gained from interactions between the environment and the subject is vital to understanding actual and potential experience. This process is known as embodied cognition (Barsalou, 1999; Glenberg, 1997).

Embodied theories of cognition predict that perceptual and motor systems are activated during language comprehension when corporal, affective, and cognitive states are elicited (Barsalou, 1999; Bonfiglioli, Finocchiaro, Gesierich, Rositani, \& Vescovi, 2009). This can happen through physical or mental simulation of such states or when they are experienced in reality. However, empirical evidence suggests that the relationship between systems and states also operates in a bidirectional fashion (e.g., Kaschak et al., 2005; Rueschemeyer, Lindemann, van Rooj, van Dam, \& Bekkering, 2010). In other words, once a particular sensory and/or motor sys- tem is triggered, it activates associated neuronal structures and activities and related bodily, affective, and cognitive states. In such activation loops, simulation has a central role in that it calls for the contents of memory and inferential processes. Additionally, in the case of all other processes, associated neuronal structures and activities are also activated (see Figure 1).

Given all the conceptual elements discussed so far it is proposed that narrative text comprehension can be seen as the construction of embodied situation models produced from simulations of the events referred to in a text. The simulations include the products of memory systems and inferential processes and all cognitive processes that are dependent on groups of neuronal structures and activities (Mishra \& Marmolejo-Ramos, 2010; Marmolejo-Ramos, 2007a, 2007b).

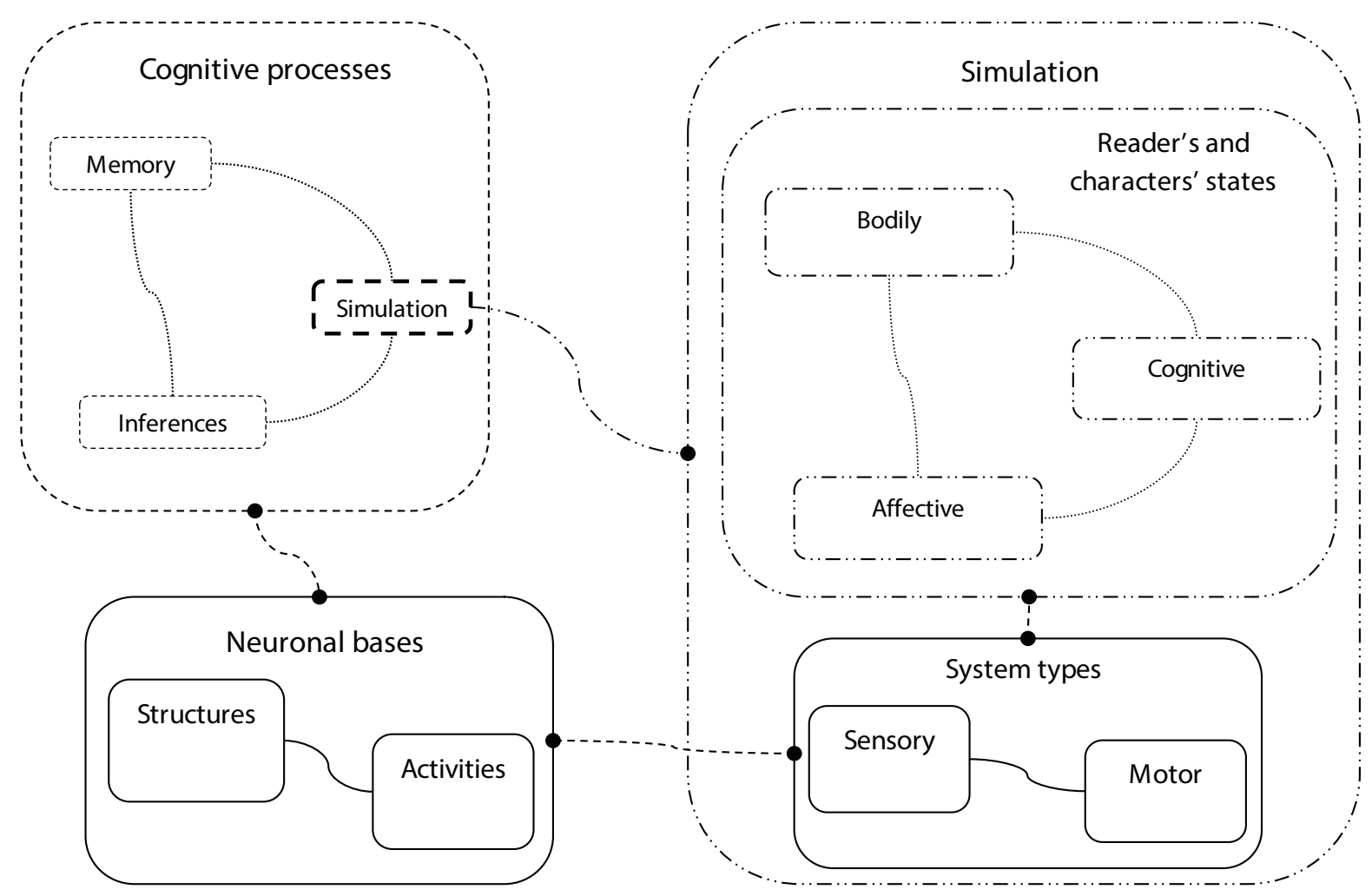

Figure 1. Neurocognitive systems and structures activated during the comprehension of texts (NCSS). Both sensory-motor systems and cognitive processes have associated neuronal activities and structures. The simulation process recruits memory resources and inferences in order to simulate bodily, affective, and cognitive states in the reader and in the characters referred to in the text.

Source: own work 


\section{The Role of Text Features in Comprehension Processes}

The model proposed so far provides for the cognitive processes that the reader performs when comprehending texts, that is, memory systems, simulation and inferential processes. However, the text per se also has features that contribute directly to the type of representation constructed. In particular, texts contain specific textual markers (e.g., style, syntactic construction, connectives, etc.) and intrinsic properties that enable their classification into genres (see, Bortolussi \& Dixon, 2003). Bortolussi and Dixon have carried out several experiments to determine the influence of such text features in the situation models created by the reader (Bortolussi \& Dixon, 2003; Dixon \& Bortolussi, 2001). One of their main findings has been the distinction between representations of the reader and those textual features that allow readers to "hook up" with the events and the plot. Among the textual features found to be vital to comprehension are content, presence of connectives, and plausibility of the events narrated.

In addition, it has also been found that through the use of literary devices such as the creation of suspense or emotion in characters (Gernsbacher, Goldsmith, \& Robertson, 1992; Gerrig, 1993; Gygax, Garnham, \& Oakhill, 2004; Gygax, Oakhill, \& Garnham, 2003; Gygax, Tapiero, \& Carruzzo, 2007; Komeda \& Kusumi, 2006), readers can build perceptual information about a story (e.g., Fisher \& Zwaan, 2008). For example, readers keep track of a protagonist's visual information during the reading of narratives (Fincher-Kiefer, 2001), but when the protagonist's perspective of the story is occluded, the readers' accessibility to the occluded objects also decreases (Horton \& Rapp, 2003). A study in which a dual task paradigm was used suggests that this is because situation model construction can be disrupted during the representation of visual images (Fincher-Kiefer, 2001).

The interaction between readers and story characters enables readers to experience the story world more vividly. In particular, the relationship between readers and protagonists is an important component of narrative text comprehension. For example, personality similarities between readers and characters explain emotional inferences and reader empathy in narrative comprehension. Extroverted readers highly estimate extroverted characters' positive emotions (Komeda, Kawasaki, Tsunemi, \& Kusumi, 2009). Furthermore, research has shown that the social conditions framing linguistic exchanges between characters influence the encoding that readers have of those linguistic exchanges (Drumm \& Klin, 2011). Thus, story $X$ in which character $A$ leaves a note for character $B$, is encoded differently from story $Y$ in which character $A$ speaks to character $B$ about the content of the note described in story $X$. This evidence suggests that readers simulate story characters' cognitive and emotional processes and that such simulations are tied to the way the events in the story are phrased.

In other words, narrative texts present linguistic information that is included in the mental representation that the reader creates and which influences the embodied situation model being built. In addition, the reader evaluates the discursive properties of the text to determine its quality (see Figure 2).

To sum up, narrative text comprehension requires the use of various cognitive and neural components in the construction of mental representations that encapsulate the content and features of the narrative (Marmolejo-Ramos, 2007a, 2007b). A central component for the construction of such representations is the reader's sensorimotor experiences with the environment (Marmolejo-Ramos et al., 2009) related to actions that can be performed on the objects, characters, and fictional environments referred to in the text (Rapp, Komeda, \& Hinze, 2011; see also, Miall, 2011; Wojciehowski \& Gallese, 2011; Zwaan et al., 1995; Zwaan \& Radvansky, 1998). Put another way, all possible combinations among elements mentioned in the text are simulated based on previous experiences in order to extract their meaning. In this process, the bodily, affective, and cognitive states previously experienced by the reader are used as the base knowledge that feeds the simulation of similar states derived from the narrative. 


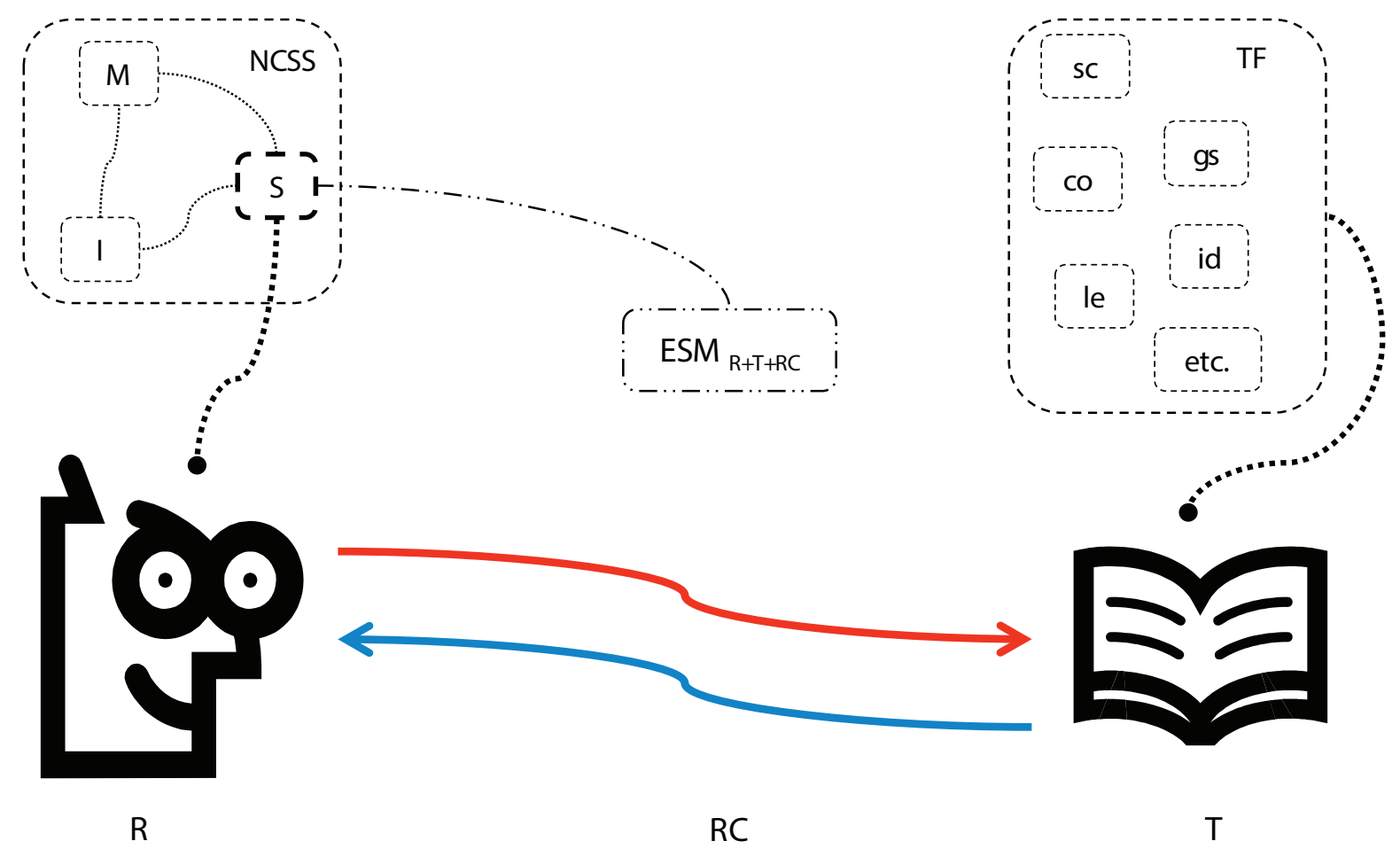

Figure 2. Interaction between reader and text during the comprehension of texts. $R=$ reader, $T=$ text, $R C=$ reading context, NCSS = neurocognitive systems and structures, $E M_{R+T+R C}=$ embodied situation model (ESM contains simulation of states and associated sensorimotor properties [i.e., bodily, affective, and cognitive states] of $R$, the scenarios, entities, characters, and actions referred to in $\mathrm{T}$, and $\mathrm{RC}$ ), and $\mathrm{TF}=$ text features (e.g., $s c=$ specific content, $c o=$ connectives, $g s=$ grammatical structure, le = length, id = idiom, etc. $=$ and other text features). $E_{R M_{R+R C}}$ is updated as new information from $T$ is obtained (blue arrow) and the latest version of the $E S M_{R+T+R C}$ is then used to understand the information given in $T$ (red arrow). ESM ${ }_{R+T+R C}$ is determined by the properties and contents of the NCSS (e.g., memory capacity and contents and inferential skills), TF (e.g., a text with poor structure might demand higher memory resources and affect the elaboration of inferences), and $\mathrm{RC}$ (e.g., reading goals and strategies, such as reading for information search versus. reading for leisure).

Source: own work

\section{The Comprehension of Texts as a Complex Thinking Process}

Cognitive processes involved in text comprehension have already been mentioned, but the question remains: Can text comprehension be considered a complex thinking process? A complex thinking process emerges when the comprehension task is proposed as a problem solving situation (PSS).

A PSS occurs when a given situation is transformed into a task situation with a specific objective as a result of there being no obvious way to resolve it (see, Simon, 1978). Text comprehension becomes a PSS when the text has to be broken down into various levels, making it the task environment. For example, the task might be to compare a text with knowledge of other texts at the level of the superstructure (i.e., to distinguish between different types of texts, e.g., narrative vs. argumentative) or at the macro structure level (e.g., distinguish central from less central ideas; see Elosúa, 2000). Additionally, the reader's reading goals and reading context can be part of the task environment in that the purpose and intention for which a text is read will also determine what information is retained and processed and the reading strategies that will be part of the problem space (see, McCrudden, Magliano, \& Schraw, 2010). Explicitly, 
information is retrieved with the aim of meeting the reader's specific goals for reading a particular text (e.g., study, entertainment) or general standards of coherence (Linderholm, Virtue, Tzeng, \& van den Broek, 2004; van den Broek, Risden, \& Husebye-Hartmann, 1995), reflecting the reader's knowledge and beliefs about what constitutes good comprehension, as well as his or her.

Once the reader represents the situation of comprehension as a task, the construction of the problem space takes place. The problem space contains specific objectives that filter incoming information (planning), the reading strategies that are deployed according to the information required (implementation), and the meta-cognitive activities that allow one to analyse the progress made during the solution of the problem (monitoring; see Mayer, 1994). The reading strategies of the reader can be defined as cognitive or behavioural actions that are enacted with the goal of improving comprehension (Graesser, 2007): a good example might be looking up an unknown word in the dictionary and re-reading a sentence with the new definition in mind. Metacognitive or monitoring activities relate to cognitive processes and knowledge necessary to confirm successful comprehension (McNamara, O'Reilly, Rowe, Boonthum, \& Levinstein, 2007). Thus, the representation of the problem space encloses representations about the narrative dimension of the text (e.g., emotional relationship between characters, characters' goals, etc), the environment of the reading situation (e.g., reading out loud and acting out the fictional situations on a small-scale scenario), and the reader him/herself (e.g., his/her own emotional states). All these aspects must be addressed concurrently by the reader and this simultaneity is an essential factor in understanding text comprehension as a PSS.

Finally, the reader must use neurocognitive systems and structures that are responsible for solving the task. In previous paragraphs, we briefly discussed the core cognitive processes involved in text comprehension (see Figure 1). It is important to re-emphasise, however, that the representation of the task environment and the problem space that the reader constructs is analogous to an embodied situation model arising from interaction between the reader's cognitive processes and aspects of the text. Any such process of simulation is an essential component in problem solving and reasoning in general (Cassimatis, Murugesan, \& Bignoli, 2009). Moreover, neuroscientific research indicates that inherent in simulations of specific goals in problem solving situations is the activation of the default network and the executive dorsolateral prefrontal cortex in order to, among other processes, coordinate motor actions in relation to goals and deal with the task's level of abstractness and emotional valence (Gerlach, Spreng, Gilmore, \& Schacter, 2011) (see Figure 3).

To fully explain how texts are processed in terms of a PSS, beyond the components of the reader's cognitive system already discussed, entails understanding how background knowledge is used during comprehension and how readers deploy metacognitive strategies to monitor comprehension (see, Stanovich \& Cunningham, 1991). Thus, a model of the cognitive processes involved in text comprehension as a PSS must include at least these two aspects. We have already discussed the use of background knowledge and its representational content, and have highlighted the role of simulation processes. We also mentioned that during the process of comprehension, the reader should monitor the reading process which is, in itself, a metacognitive strategy. With this in mind, we propose a sequence of steps that occur during the comprehension of texts seen as a PSS.

The present scheme is based on a cognitive model for problem solving proposed by Wang and Chiew (2010) because it includes low-level (e.g., sensorimotor systems) and high-level (e.g., inferences) cognitive processes to represent the human brain. The model proposed herein is a modified version specifically suited for text comprehension. Moreover, both Wang and Chiew's original model (W\&C) and the one proposed here have properties of other neurocognitive models based on current advances in neuroscience and cognitive science (e.g., Marmolejo-Ramos et al., 2012). However, the current model differs from W\&C in that a stronger emphasis is placed on the cognitive pro- 


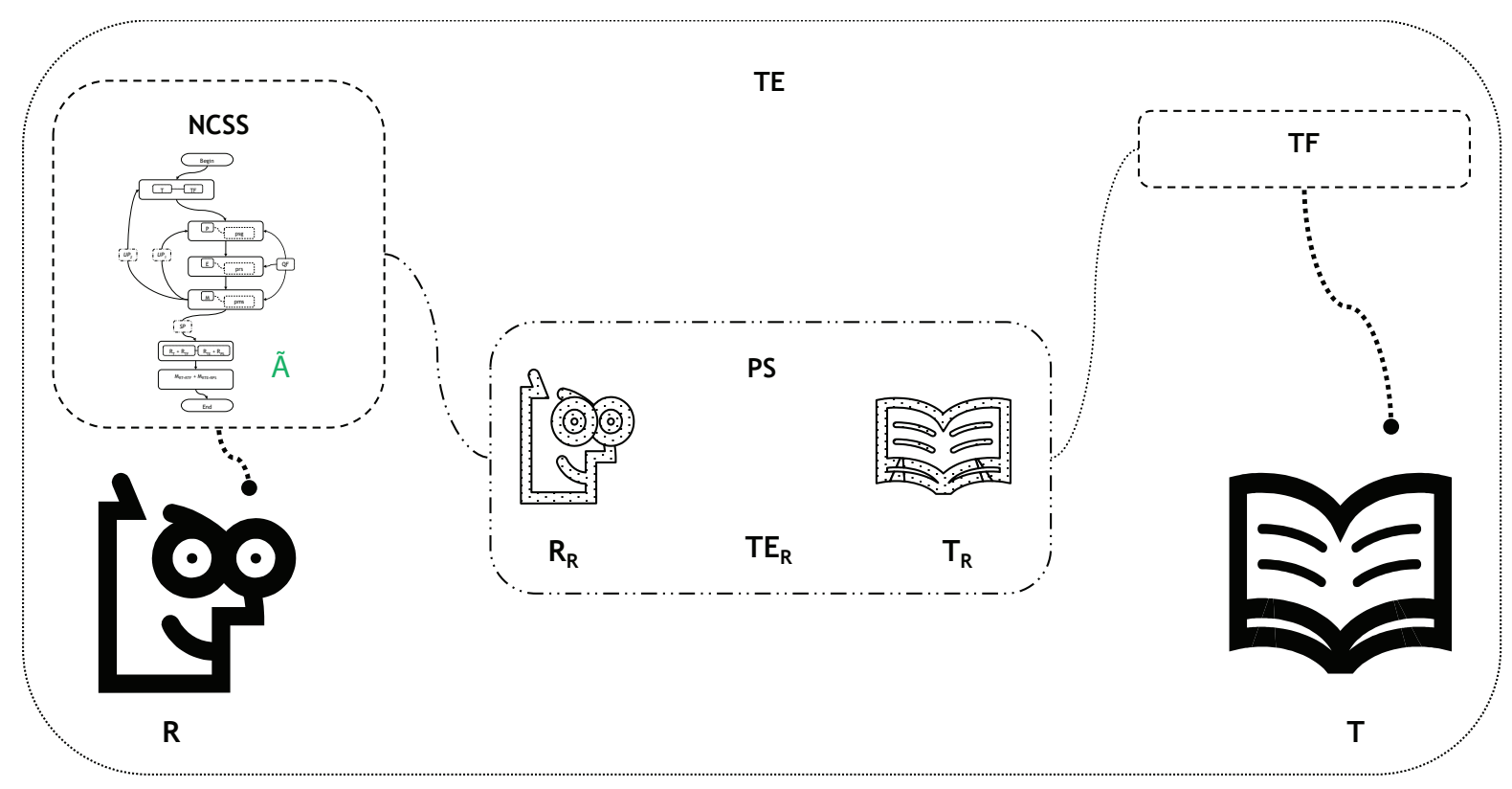

Figure 3. Basic components and processes implied in text comprehension as a problem solving situation. $R=$ Reader, $R_{R}$ $=$ Reader representation, $T=$ Text, $T_{R}=$ Text representation, $T F=$ text features, NCSS $=$ neurocognitive systems and structures, $P S=$ problem space, $\mathrm{TE}=$ task environment, and $\mathrm{TE}_{\mathrm{R}}=$ representation of the task environment. $R$ represents TE, $T$ and $R$ itself in PS. PS has the properties of an embodied situation model in that it embeds simulation of states and associated sensorimotor properties of $R\left(\right.$ i.e., $\left.R_{R}\right)$, the scenarios, entities, characters, and actions referred to in $T$ (i.e., $\left.T_{R}\right)$, and the environment of the reading situation (i.e., $T E_{R}$ ). NCSS use specific cognitive processes $(\tilde{A})$ in order to comprehend texts when comprehension is made analogous to a problem solving situation.

Source: own work

cesses supporting problem solving. Expressly, new proposals from the situated cognition framework are incorporated (see, Kirsch, 2009); namely, that the problem to be solved is grounded in a specific setting and that the comprehender uses sensorimotor knowledge and experience in the simulation process. More importantly, in the present modified model the formulation of questions is explicitly introduced as a component that adds interactivity to the problem solving process (see below).

As Figure 4 illustrates, the process begins with the identification of the text type and its features ( $T$ and TF). Subsequently, reading goals $(P)$ are determined, which requires in turn the estimation of possible solutions to achieve the goals (psg). The particular type of reading based on the selected goals is then executed $(E)$ and possible reading strategies (prs) are determined. The ongoing reading process is reviewed $(M)$ using various meta-cognitive strategies (pms). If the process is unsatisfactory at any of the previous stages, the reader has two options: he or she may repeat the process from the reading goals $\left(U P_{1}\right)$, or from the identification of the text and its intrinsic features $\left(\mathrm{UP}_{2}\right)$. If the results of the previous steps are satisfactory (SP), the construction of representations of both the text and its features $\left(R_{\mathrm{T}}+R_{\mathrm{TF}}\right)$ takes place. All representations constructed are stored in memory systems to be used in future reading situations $\left(\mathrm{M}_{R T+R T F}\right)$.

Text comprehension seen as a PSS implies that as the demands of the reading situation increase, thinking processes become more complex (see, Nelson-Legall \& Resnick, 1998). One factor that influences the reading situation is the formulation of questions (QF). Research in discourse comprehension has shown that QF helps to structure and interpret discourse by positing implicit and explicit queries such as examples and contradictions, etc. that require an answer (see, Clifton \& Frazier, 2012). Thus, the reader who can ask questions 
about a text integrates information processed up until that point, to maximize inferences, to anticipate, and to search for information. Similarly, QF allows the reader to relate the textual information with previous knowledge based on his or her experience. QF plays a key role especially in the representation of the problem space, and particularly when goals, reading strategies, and metacognitive strategies are being determined. For example, during the execution of reading, asking questions helps to filter the information presented in the text and this in turn affects the kinds of inferences that are made, the contents to be remembered, and the simulations of the events referred to in the text. In

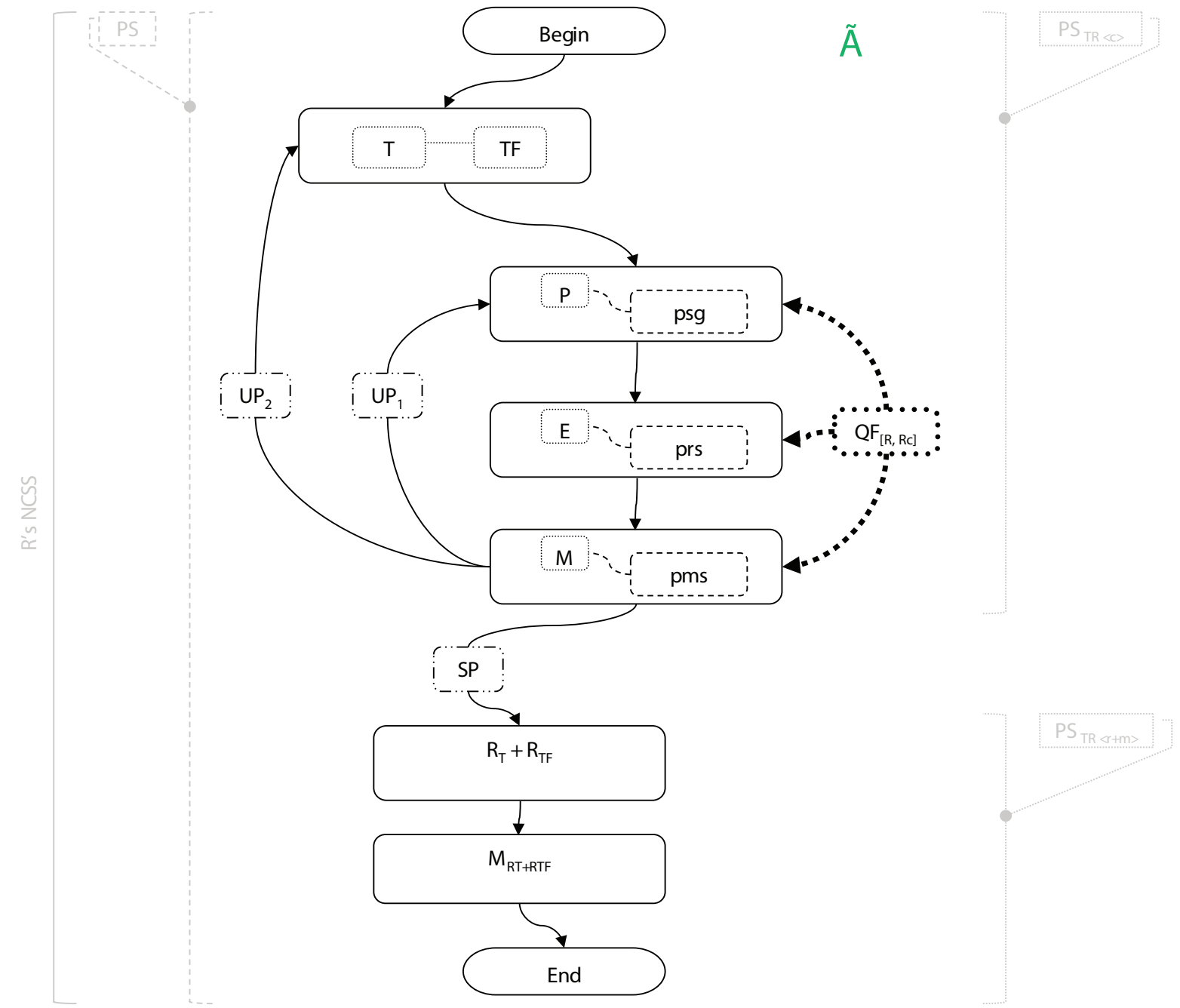

Figure 4. Cognitive processes implied in text comprehension as a problem solving situation ( $\tilde{A}) . T=T e x t, T F=$ Text features, $P=$ Planning, $E=$ Executing, $M=$ Monitoring, $R_{T}+R_{T F}=$ Representation of text and text features, $M_{R T+R T F}=$ Memory of representation of text and text features, $S P=$ satisfactory process, $U P_{1}=$ unsatisfactory process - option $1, U_{2}$ $=$ unsatisfactory process - option 2, psg = possible solutions to achieve goals, prs $=$ possible reading strategies, pms $=$ pos sible metacognitive strategies, $P S_{T R<c>}=$ construction of the text representation in the problem space, $P S_{T R<r+m>}=$ final representation and memory of the text representation in the problem space, and $\mathrm{QF}_{[R, R c]}=$ question formulation (self-generated $[R]$ and/or externally-generated questions $[R c])$. The level of completeness and accuracy of the steps in $\tilde{A}$ are highly determined by the reader's neurocognitive systems and structures (R's NCSS) and the quality of QF generated. Although R's NCSS highly determines the processes in Â, the problem space (PS) plays a key role in the steps prior to the consolidation of representations and memory traces.

Source: own work 
addition, questions can serve as cues that help to formulate a plan to solve the problem at hand (see, Gerlach et al., 2011). QF further adds a component of interactivity to PSS in that the reader does not have to always be the formulator of the questions, therefore allowing for the use of external resources (e.g., a peer can help to formulate questions). Accessing external resources via QF is a core component in the PSS in that it can lead to the use of external representations (e.g., note taking while reading). As has been documented, external representations are a more natural representation of structure than are mental representations and they amplify the comprehension process by: i) facilitating the generation of inferences, ii) materialising thinking by creating persistent referents, iii) facilitating representation and computation by the use of arbitrarily complex structures, and iv) lowering the cost of controlling thought (Kirsch, 2010) (see Figure 4).

Figure 4 also shows that the specific cognitive processes used during text comprehension as a PSS ( $\tilde{A})$ depend directly on the properties and contents of the general neurocognitive systems and structures used during the comprehension of texts (NCSS). This assumption thus indicates that NCSS are activated from the initial to the final steps during $\tilde{A}$, and that NCSS's limitations determine the contents and products of $\tilde{A}$. For instance, if the reader's NCSS has limited working memory capacity, then the final recall of the representation of the text and its features will be affected. Likewise, simulation processes rely on memory resources and inferential skills in order to predict the results of executing a plan and conceiving alternative plans of action (see, Hayes-Roth \& Hayes-Roth, 1979). Thus, lower simulation skills can lead to conceiving fewer possible solutions to achieve goals and fewer possible reading strategies.

Since Ã accounts for cognitive processes carried out to comprehend texts in the context of a PSS, $\tilde{A}$ can be seen as a means to generate a representation of the text and its features. Thus, $\tilde{A}$ leads to the construction of the text representation in the problem space (see Figure 3) in two stages: the first stage constitutes the construction of the text representation in the problem space $\left(P S_{T R<c>}\right)$; and the second stage is the final representation and memory of the text representation in the problem space ( $P S_{T R<r+m>}$ ) (see Figure 4). It is important to bear in mind that $\tilde{A}$ is a very specific process to achieve $T_{R}$ in the $P S$, and since $P S$ contains other elements, i.e., $T E_{R}$ and $R_{R}$, a successful Ã cannot occur without accounting for the effects of those elements.

One of the main and unique characteristics of $\tilde{A}$ is the inclusion of QF. Limitations of the reader's NCSS could be attenuated by self-generated high-quality QFs; however, once again, intrinsic NCSS limitations could affect the quality of the self-generated questions. The solution to this situation hinges on the premise that QF adds interactivity to $\tilde{\mathrm{A}}$ by allowing the use of external resources. This assumption thus predicts that NCSS limitations could be minimised by having a peer formulate questions. Thus, QF by a peer can enhance monitoring processes by formulating questions that point to planning and executing strategies or, more broadly, that cue metacognitive strategies (see Figure 4).

\section{Discussion}

It has been proposed that text comprehension can be understood as a problem solving situation, involving the interaction of cognitive processes and the features of texts with reasons given above.

Hence, research in narrative text comprehension needs to consider the current advances in cognitive science, particularly that text comprehension can be seen as problem solving from the embodied cognition framework. As highlighted previously (Marmolejo-Ramos et al., 2009), there is mounting empirical evidence that the comprehension of narrative texts entails the activation of perceptual and motor brain systems. Indeed, recent studies in which story-like linguistic units have been employed (see, Speer et al., 2009; Zacks, Speer, Swallow, \& Maley, 2010) confirm the evidence based on words, sentences, or very short texts presented here.

There is, however, some varying evidence regarding cognitive processes and the brain systems 
elicited during the comprehension of narrative-like linguistic material. For instance, evidence shows that, under specific experimental settings, some types of inferences called bridging inferences, are generated even more easily during the processing of expository than narrative texts (Baretta et al., 2009), even though it is well-known that, overall, narrative texts enhance the generation of inferences (Graesser, León, \& Otero, 2002). This could be significant in the contradiction that while most brain imaging studies show that concrete concepts embedded in sentences invoke sensorimotor systems (e.g., Moody \& Gennari, 2010), others fail to replicate such claims (e.g., Raposo, Moss, Stamatakis, \& Tyler, 2009).

One explanation for this is recent evidence which shows that the recruitment of sensorimotor systems minimises as sentences move from literal/concrete to metaphoric/abstract (see, Desai, Binder, Conant, Mano, \& Seidenberg, 2011). These results suggest the experimental materials themselves, that is, the texts used in the studies have an effect on the cognitive processes elicited. This would not only corroborate the elicitation of cognitive processes and brain systems during the comprehension of stories, but also indicate that the reading materials and reading requirements determine which brain areas are activated and how texts are processed.

\section{Text Comprehension as PSS and Discourse Genres}

Although this paper focused on the specific case of narrative texts, the cognitive processes and the comprehension of texts as a PSS can be readily extended to the cases of expository and argumentative texts. For instance, in regard to the former, it has been shown that verbalising thoughts aloud increases comprehension (Gillam, Fargo, \& Robertson, 2009), and that question format (e.g., open-ended vs. Multiple-choice) affects the comprehension process (Ozuru, Best, Bell, Whiterspoon, \& McNamara, 2007). Both think-loud and question format relate to the QF component in the model proposed herein. Specifically, think-loud can be seen as an essential by-product of external representation in the QF process while how a question is worded and structured... To the best of our knowledge, these issues have not been studied thoroughly in relation to the comprehension of narrative texts. Presumably, this is because the ease with which narratives are understood is taken for granted (León, Escudero, \& van den Broek, 2003). Hence, determining the role that QF plays in the comprehension of narrative texts is an issue that calls for further research. It could be that the QF component of the current cognitive model could play a key role in enhancing the comprehension of argumentative texts, the key elements of which evidence suggests readers find it hard to identify (Larson, Britt, \& Larson, 2004).

\section{Comprehension as Problem Solving and Spoken Discourse}

Models of discourse comprehension have tended to focus on written discourse. In comparison, little attention has been paid to the construction of a coherent representation during the processing of spoken discourse (Cevasco, 2008; Cevasco \& van den Broek, 2008; Zwann \& Rapp, 2006; Speer \& Blodgett, 2006).

In consequence, it would be interesting to consider whether spoken discourse comprehension can also be approached as a problem solving situation. If so, a listener would also approach spoken discourse with a comprehension goal that is part of a task environment. For example, a goal might be to listen to a class in order to perform better at an exam. This goal could also lead to comprehension strategies, such as taking notes, and to the listener monitoring if he or she is constructing a coherent discourse representation. The problem space could be extended with the comprehender needing to solve tasks specific to spoken discourse, such as processing disfluencies (Brennan \& Schober, 2001; Fox Tree, 1995; Lickley \& Bard, 1998) and prosodic cues (Allbritton, McKoon, \& Ratcliff, 1996; Kraljic \& Brennan, 2005; Schafer, Speer, Warren, \&White, 2000). 


\section{Application of the Model to Educational Settings}

Models that allow us to think about the processes that take place during text comprehension are useful tools for the field of education as successful comprehension of texts is crucial for student learning (McCrudden, 2012; van den Broek \& Kendeou, 2008). It has been shown that the likelihood of successfully resolving a task is higher when people are required to perform directed body movements that somehow relate to the task at hand than when they perform unrelated body movements (Thomas \& Lleras, 2009; see also, Slepian \& Ambady, 2012). The underlying idea of this finding could be used to facilitate comprehension and retention of narrative texts. Based on work suggesting that objects and/ or toy manipulation enhance comprehension of the spatial dimension in short stories by children (see, Glenberg, Brown, \& Levin, 2007; Glenberg, Goldberg, \& Zhu, 2011; Glenberg, Gutierrez, Japuntich, \& Kaschak, 2004; Marley, Szabo, Levin, \& Glenberg, 2011), it has been proposed that such manipulation activity could also enhance comprehension of the emotional dimension (Marmolejo-Ramos, 2004, 2007a, 2007b; Marmolejo-Ramos \& Jiménez, 2005). To be precise, it could be possible that even abstract concepts (e.g., emotions) can be grounded in concrete actions in order to increase their comprehension. Framing comprehension as a PSS and introducing kinaesthetic strategies or questions could be instrumental in this regard.

The cognitive model of text comprehension as a PSS (see Figures 1 to 4) can clearly be applied to educational settings that aim to enhance the comprehension of abstract concepts embedded in texts. Based on developmental research suggesting that sensorimotor processes lay the foundations for semantic organisation of concrete concepts (Antonucci \& Alt, 2011), it can be entertained that semantic organisation of abstract concepts can also benefit from sensorimotor processes. Developmental research has also shown that although 3 and 4 year old children comprehend emotion concepts presented in narratives, they use different inferential strategies and sources of knowledge (Mar-
molejo-Ramos \& Jiménez, 2006). Thus, children's comprehension of abstract concepts embedded in texts can be facilitated by the use of QFs that focus on different components of the reading situation, i.e., components represented in the PS, and which are combined with sensorimotor activities.

To exemplify this, let us envisage a reading situation in which the task is to determine the actions and events that lead to emotional changes in the characters of a story (i.e., the reading situation's TE). For this purpose, children can be presented with toys and a small-scale scenario representing characters, objects, and the settings of a story, while an adult (e.g. the teacher) reads the story aloud. Children participating in the activity can be given specific characters to play so that, as the story unfolds, they act out the actions and the events.

The PS for the comprehension activity can be constructed in various ways that combine QFs, elements of the TE, and the $R$ him/herself. For example, the sensorimotor activity of manipulating the toys in the scenario can be coupled with QFs from the teacher $\left(\mathrm{QF}_{R c}\right.$ in Figure 4) that lead children to consider: i) possible aspects of the story that are relevant to understanding characters' emotions; ii) possible segmentations of the text based on characters' emotional changes; and iii) possible physical characteristics of the characters, events, and actions that help to monitor whether, a) the actions occur in the order in which they are described in the narrative, and b) whether a specific emotional state has ended so that another one can occur. These potential QFs relate to psg, prs, and pms in $\tilde{A}$, and in all cases the reader's bodily, affective, and cognitive states are used to inform the construction of $T_{R}$, via $\tilde{A}$, in the PS. A more complex form of the TE presented herein, which would thus be more suitable for older children, would be that in which children determine how emotions are conceived in the text via the relationship between author, characters, and the readers themselves (see, Poyatos, 1977). A recently proposed cognitive model of spontaneous discourse (Cevasco \& Marmolejo-Ramos, 2013) presents empirical evidence as to how kinesics (i.e., bodily actions) coupled with language and paralanguage enhance language comprehension 
and production. In relation to the current case, this suggests that activity-based text comprehension can be combined with QF to lead children to consider specific kinesic and paralinguistic factors that accompany characters' emotions. However, empirical evidence regarding the examples considered herein, to the best of our knowledge, has not been obtained from children and adult populations, let alone those with sensorimotor impairments.

\section{Potential Computational Implementations}

It has become common practice in text comprehension research to generate computational models of comprehension that support collected empirical data in making predictions. There have been various models proposed thus far (e.g., Lemaire, Denhière, Bellissens, \& Jhean-Larose, 2006; Tzeng, van den Broek, Kendeou, \& Lee, 2005) that operate in response to specific rules and lead to reliable predictions (e.g., Molinari, Barreyro, Cevasco, \& van den Broek, 2011). We believe the following rules could be included in a computational model of text comprehension as a PSS: R1: world knowledge is stored in memory, $R 2$ : world knowledge is made up of concepts, $R 3$ : linguistic concepts (knowledge) have perceptual and motor information attached to them (this is assumed because perceptual and motor experience cannot be explicitly modelled) (see, Louwerse, 2008), R4: concepts are defined by their relationships with other concepts via semantic associations, and R5: the relationships between and within concrete and abstract concepts (see, Wiemer-Hastings \& Xu, 2005) are also achieved via semantic associations (this being a core element in the processing of metaphors). Most importantly, we believe that including QF in a computational implementation could assist in recovering key concepts essential for the understanding of the text.

Although there is a lack of empirical work that directly supports this model in its entirety, the empirical evidence reviewed in relation to specific parts of the model suggests that its foundations are well grounded. For instance, as reported above, there are behavioural and neuroimaging results indicating that $\mathrm{QF}$ is essential in structuring and interpreting discourse and in helping to formulate a plan to solve the problem at hand. Additionally, evidence was presented in support of other components of the model, such as memory, inferences, and simulation,. Such evidence, when pieced together, suggests that the model proposed herein can be readily tested. One of the current challenges though is to furnish laboratory- and ecologically-valid experiments that can attest the mechanics of the model.

\section{Conclusion}

In sum, we propose a cognitive model of text comprehension in terms of a PSS by combining a classic model of the structure of problem situations with a recent cognitive model for problem solving. Although the model relies on well-known cognitive components such as inferences, memory, and simulations, QF is included as a component that boosts representational power. Seeing text comprehension as a PSS opens new research avenues, particularly in relation to text and cognition, in that it brings the text and the reader together into a situation where high-order cognitive processes are needed. A potential implementation of a computational model is outlined.

\section{References}

Allbritton, D., McKoon, G., \& Ratcliff, R. (1996). Reliability of prosodic cues for resolving syntactic ambiguity. Journal of Experimental Psychology: Learning, Memory, $\mathcal{E}$ Cognition, 22(3), 714-735.

Antonucci, S. M., \& Alt, M. (2011). A lifespan perspective on semantic processing of concrete concepts: Does a sensory/motor model have the potential to bridge the gap? Cognitive, Affective, $\mathcal{B}$ Behavioral Neuroscience, 11(4), 551-572.

Baddeley, A. (2010). Working memory. Current Biology, 20(4), R136-R140.

Baretta, L., Tomitch, L. M. B., MacNair, N., Lim, V. K., $\&$ Waldie, K. E. (2009). Inference making while 
reading narrative and expository texts: An ERP study. Psychology $\mathbb{E}$ Neuroscience, 2(2), 137-145.

Barsalou, L. W. (1999). Perceptual symbol systems. Behavioral and Brain Sciences, 22(4), 577-660.

Bonfiglioli, C., Finocchiaro, C., Gesierich, B., Rositani, F., \& Vescovi, M. (2009). A kinematic approach to the conceptual representations of this and that. Cognition, 111(2), 270-274.

Bortolussi, M., \& Dixon, P. (2003). Psychonarratology: Foundations for the empirical study of literary response. Cambridge: Cambridge University Press.

Bower, G. H., \& Morrow, D. G. (1990). Mental models in narrative comprehension. Science, 247(4938), 44-48.

Brennan, S., \& Schober, M. (2001). How listeners compensate for disfluencies in spontaneous speech. Journal of Memory and Language, 44(2), 274-296.

Brunyé, T. T., Ditman, T., Mahoney, C. R., \& Taylor, H. A. (2011). Better you than I: perspectives and emotion simulation during narrative comprehension. Journal of Cognitive Psychology, 23(5), 659-666.

Carretti, B., Borella, E., Cornoldi, C., \& De Beni, R. (2009). Role of working memory in explaining the performance of individuals with specific reading comprehension difficulties: A meta-analysis. Learning and Individual Differences, 19(2), 246-251.

Cassimatis, N. L., Murugesan, A., \& Bignoli, P. G. (2009). Reasoning as simulation. Cognitive Processing, 10(4), 343-353.

Cevasco, J. (2008). La importancia del estudio de la comprensión de discurso a través de la utilización de materiales de discurso oral espontáneo. Investigaciones en Psicología, 13(2), 45-60.

Cevasco, J., \& Marmolejo-Ramos, F. (2013). The importance of studying prosody in the comprehension of spontaneous spoken discourse. Revista Latinoamericana de Psicología, 45(1), 21-33.

Cevasco, J., \& van den Broek, P. (2008). The importance of causal connections in the comprehension of spontaneous spoken discourse. Psicothema, 20(4), $801-806$

Clifton, C., \& Frazier, L. (2012). Discourse integration guided by the 'question under discussion'. Cognitive Psychology, 65(2), 352-379.
Cook, A. E., Guéraud, S., Was, C., \& O’Brien, E. J. (2007). Foregrounding effects during reading, revisited. Discourse Processes, 44(2), 91-11.

de Vega, M. (1984). Introducción a la psicología cognitiva. Madrid: Alianza Editorial.

de Vega, M., \& Cuetos, F. (1999). Psicolingüística del español. Madrid: Editorial Trotta, S. A.

Deen, B., \& McCarthy, G. (2010). Reading about the actions of others: Biological motion imagery and action congruency influence brain activity. Neuropsychologia, 48(6), 1607-1615.

Desai, R. H., Binder, J. R., Conant, L. L., Mano, Q. R., \& Seidenberg, M. S. (2011). The neural career of sensory-motor metaphors. Journal of Cognitive Neuroscience, 23(9), 2376-2386.

Ditman, T., Brunyé, T. T., Mahoney, C. R., \& Taylor, H. (2010). Simulating an enactment effect: Pronouns guide action simulation during narrative comprehension. Cognition, 115(1), 172-178.

Dixon, P., \& Bortolussi, M. (2001). Prolegomena for a science of psychonarratology. In W. van Peer \& S. Chatman (Eds.), New perspectives on narrative perspective (pp. 275-287). Albany, NY: S.U.N.Y. Press.

Drumm, A. P., \& Klin, C. M. (2011). When story characters communicate: Readers' representations of characters' linguistic exchanges. Memory $\mathcal{E} \mathrm{Cog}$ nition, 39(7), 1348-1357.

Elosúa, M. R. (2000). Procesos de la comprensión, memoria y aprendizaje de textos. Madrid: Editorial Sanz y Torres, S. L.

Fincher-Kiefer, R. (2001). Perceptual components of situation models. Memory $\mathbb{E}$ Cognition, 29(2), 336-343.

Fischer, M. H., \& Zwaan, R. A. (2008). Embodied language: $\mathrm{A}$ review of the role of the motor system in language comprehension. Quarterly Journal of Experimental Psychology, 61(6), 825-850.

Fox Tree, J. E. (1995). The effects of false starts and repetitions on the processing of subsequent words in spontaneous speech. Journal of Memory and Language, 34(6), 709-738.

Gallese, V., \& Sinigaglia, C. (2011). What is so special about embodied simulation? Trends in Cognitive Sciences, 15(11), 512-519.

Gerlach, K. D., Spreng, R. N., Gilmore, A. W., \& Schacter, D. L. (2011). Solving future problems: 
Default network and executive activity associated with goal-directed mental simulations. Neurolmage, 55(4), 1816-1824.

Gernsbacher, M. A., Goldsmith, H. H., \& Robertson, R. R. W. (1992). Do readers mentally represent characters' emotional states? Cognition and Emotion, 6(2), 89-111.

Gerrig, R. J. (1993). Experiencing narrative worlds: On the psychological activities of reading. New Haven: Yale University Press.

Gillam, S. L., Fargo, J. D., \& Robertson, K. St. C. (2009). Comprehension of expository text: Insights gained from think-aloud data. American Journal of Speech-Language Pathology, 18, 82-94.

Glenberg, A. (1999). Why mental models must be embodied. In G. Rickheit \& C. Habel (Eds.), Mental Models in discourse processing and reasoning (pp. 77-90). Amsterdam, Netherlands: North-Holland/ Elsevier Science Publishers.

Glenberg, A. M. (1997). What memory is for. Behavioral Ë Brain Sciences, 20(1), 1 -55.

Glenberg, A. M., Brown, M., \& Levin, J. R. (2007). Enhancing comprehension in small reading groups using a manipulation strategy. Contemporary Educational Psychology, 32(3), 389-399.

Glenberg, A. M., Goldberg, A., \& Zhu, X. (2011). Improving early reading comprehension using embodied CAI. Instructional Science, 39(1), 27- 39.

Glenberg, A. M., Gutierrez, T., Levin, J. R., Japuntich, S., \& Kaschak, M. P. (2004). Activity and imagined activity can enhance young children's reading comprehension. Journal of Educational Psychology, 96(3), 424-436.

Graesser, A. C. (2007). An introduction to strategic reading comprehension. In D. S. McNamara (Ed.), Reading comprehension strategies: Theories, interventions, and technologies (pp. 3-26). Mahwah, NJ: Lawrence Erlbaum.

Graesser, A. C., \& Wiemer-Hastings, K. (1999). Situation models and concepts in story comprehension. In S. R. Goldman, A. C. Graesser, \& P. van den Broek (Eds.), Narrative comprehension, causality, and coherence: Essays in honor of Tom Trabasso (pp. 77-92). Mahwah, NJ: Erlbaum.

Graesser, A. C., León, J. A., \& Otero, J. C. (2002). Introduction to the psychology of science text comprehension. In J. C. Otero, J. A. León, \& A. C. Graesser (Eds.), The psychology of science text comprehension (pp. 1-15). Mahwah, NJ: Lawrence Erlbaum Associates.

Graesser, A. C., Millis, K. K., \& Zwaan, R. A. (1997). Discourse comprehension. Annual Review of Psychology, 48(1), 163-189.

Guéraud, S., Tapiero, I., \& O’Brien, E. J. (2008). Context and the activation of predictive inferences. Psychonomic Bulletin and Review, 15(2), 351-356.

Gygax, P., Garnham, A., \& Oakhill, J. (2004). Inferring characters' emotional states. Can readers infer specific emotions? Language and Cognitive Processes, 19(5), 613-639.

Gygax, P., Oakhill, J., \& Garnham, A. (2003). The representation of characters' emotional responses. Do readers infer specific emotions? Cognition and Emotion, 17(3), 413-428.

Gygax, P., Tapiero, I., \& Carruzzo, E. (2007). Emotion inferences during reading comprehension: What evidence can the self-pace reading paradigm provide? Discourse Processes, 44(1), 33-50.

Hayes-Roth, B., \& Hayes-Roth, F. (1979). A cognitive model of planning. Cognitive Science, 3(4), 275-310.

Hesslow, G. (2002). Conscious thought as simulation of behavior and perception. Trends in Cognitive Sciences, 6(6), 242-247.

Horton, W. S., \& Rapp, D. N. (2003). Out of sight, out of mind: Occlusion and the accessibility of information in narrative comprehension. Psychonomic Bulletin E Review, 10(1), 104-110.

Kaschak, M. P., Madden, C. J., Therriault, D. J., Yaxley, R. H., Aveyard, M. E., Blanchard, A. A., \& Zwaan, R. A. (2005). Perception of motion affects language processing. Cognition, 94(3), B79-B89.

Kintsch, W., \& Mangalath, P. (2011). The construction of meaning. Topics in Cognitive Sciences, 3(2), 346-370.

Kirsch, D. (2009). Problem solving and situated cognition. In P. Robbins \& M. Aydede (Eds.), The Cambridge handbook of situated cognition (pp. 264 306). Cambridge: CUP.

Kirsch, D. (2010). Thinking with external representations. AI Eु Society, 25(4), 441-454. 
Kneepkens, E. W. E. M., \& Zwaan, R. A. (1995). Emotions and literary text comprehension. Poetics, 23(1-2), 125-138.

Komeda, H., \& Kusumi, T. (2006). The effect of a protagonist's emotional shift on situation model construction. Memory Eु Cognition, 34(7), 1548-1556.

Komeda, H., Kawasaki, M., Tsunemi, K., \& Kusumi, T. (2009). Differences between estimating protagonists' emotions and evaluating readers' emotions in narrative comprehension. Cognition and Emotion, 23(1), 135-151.

Kraljic, T., \& Brennan, S. (2005). Prosodic disambiguation of syntactic structure: For the speaker or for the addressee? Cognitive Psychology, 50(2), 194-231.

Larson, M., Britt, M. A., \& Larson, A. A. (2004). Disfluencies in comprehending argumentative texts. Reading Psychology, 25(3), 205-224.

Lassonde, K. A., \& O'Brien, E. J. (2009). Contextual specificity in the activation of predictive inferences. Discourse Processes, 46(5), 426-438.

Lemaire, B., Denhière, G., Bellissens, C., \& Jhean-Larose, S. (2006). A computational model for simulating text comprehension. Behavior Research Methods, 38(4), 628-637.

León, J. A., Escudero, I., \& van den Broek, P. (2003). La influencia del género del texto en el establecimiento de inferencias. In J. A. León (Ed.), Conocimiento y discurso (pp. 153-170). Madrid: Pirámide.

Lickley, R., \& Bard, E. (1998). When can listeners detect disfluency in spontaneous speech? Language and Speech, 41(2), 203-226.

Linderholm, T., Virtue, S., Tzeng, Y., \& van den Broek, P. (2004). Fluctuations in the availability of information during reading: Capturing cognitive processes using the landscape model. Discourse Processes, 37(2), 165-186.

Louwerse, M. M. (2008). Embodied relations are encoded in language. Psychonomic Bulletin 8 Review, 15(4), 838-844.

Mar, R. A. (2004). The neuropsychology of narrative: Story comprehension, story production and their interrelation. Neuropsychologia, 42(10), 1414-1434.

Mar, R. A. (2011). The neural bases of social cognition and story comprehension. Annual Review of Psychology, 62(1), 103-134.
Marley, S. C., Szabo, Z., Levin, J. R., \& Glenberg, A. M. (2011). Investigation of an activity-based text-processing strategy in mixed-age child dyads. The Journal of Experimental Education, 79(3), 340-360.

Marmolejo-Ramos, F. (2004). Niños de edad preescolar en la escuela pública. ¿Qué retos proponen? Fundamentos en Humanidades, 2(10), 9-30.

Marmolejo-Ramos, F. (2007a). Niños con dificultades en la escuela. El trabajo con textos narrativos como una forma de intervención. Psychologica, 44, 97-109.

Marmolejo-Ramos, F. (2007b). Nuevos avances en el estudio científico de la comprensión de textos. Universitas Psychologica, 6(2), 331-343.

Marmolejo-Ramos, F., Elosúa de Juan, M. R., Gygax, P., Madden, C., \& Mosquera, S. (2009). Reading between the lines: The activation of embodied background knowledge during text comprehension. Pragmatics 8 Cognition, 17(1), 77-107.

Marmolejo-Ramos, F., \& Jiménez, A. T. (2005). La formación en competencias ciudadanas en el preescolar. Apuntes de Psicología, 23(2), 219-226.

Marmolejo-Ramos, F., \& Jiménez, A. T. (2006). Inferencias, modelos de situación y emociones en textos narrativos. El caso de los niños de edad preescolar. Revista Intercontinental de Psicología y Educación, 8(2), 93-138.

Marmolejo-Ramos, F., Velasco, C., Salgado-Montejo, A., Mishra, R., Aravena, P., Ibañez, A., \& Matlock, T. (2012). Towards a neurocognitive architecture of language, vision, and emotion comprehension. Manuscript in preparation.

Mayer, R. E. (1994). Problem solving. In M. W. Eysenck (Ed.), The blackwell dictionary of cognitive psychology (pp. 284-288). Oxford: Blackwell Publishers.

McCrudden, M. T. (2012). Readers' use of online discrepancy resolution strategies. Discourse Processes, 49(2), 107-136.

McCrudden, M. T., Magliano, J. P., \& Schraw, G. (2010). Exploring how relevance instructions affect personal reading intentions, reading goals and text processing: A mixed methods study. Contemporary Educational Psychology, 35(4), 229-241.

McNamara, D. S., \& Magliano, J. P. (2009). Towards a comprehensive model of comprehension. In B. 
Ross (Ed.), The psychology of learning and motivation (Vol. 51, pp. 297-284). New York: Elsevier Science. McNamara, D. S., \& McDaniel, M. A. (2004). Suppressing irrelevant information: Knowledge activation or inhibition? Journal of Experimental Psychology: Learning, Memory, and Cognition, 30(2), 465-482.

McNamara, D. S., \& O'Reilly, T. (2009). Theories of comprehension skill: Knowledge and strategies versus capacity and suppression. In A. M. Columbus (Ed.), Advances in psychology research (Vol. 62, pp. 113-136). Hauppauge, NY: Nova Science Publishers, Inc.

McNamara, D. S., \& Scott, J. L. (2001). Working memory capacity and strategy use. Memory $\mathbb{E}$ Cognition, 29(1), 10-17.

McNamara, D. S., O'Reilly, T., Rowe, M., Boonthum, C., \& Levinstein, I. B. (2007). iSTART: A web-based tutor that teaches self-explanation and metacognitive reading strategies. In D. S. McNamara (Ed.), Reading comprehension strategies: Theories, interventions, and technologies (pp. 397-421). Mahwah, NJ: Erlbaum.

Miall, D. S. (2011). Enacting the other: Towards an aesthetic of feeling in literary reading. In P. Goldie \& E. Schellekens (Eds.), The aesthetic mind: Philosophy and psychology (pp. 285-298). Oxford: Oxford University Press.

Millis, K. K., Magliano, J. P., \& Todaro, S. (2006). Measuring discourse-level processes with verbal protocols and latent semantic analysis. Scientific Studies of Reading, 10(3), 251-283.

Mishra, R. K., \& Marmolejo-Ramos, F. (2010). On the mental representations originating during the interaction between language and vision. Cognitive Processing, 11(4), 295-305.

Molinari, C., Barreyro, J. P., Cevasco, J., \& van den Broek, P. W. (2011). Generation of emotional inferences during text comprehension: Behavioral data and implementation through the landscape model. Escritos de Psicologia, 4(1), 9-17.

Moody, C. L., \& Gennari, S. P. (2010). Effects of implied physical effort in sensory-motor and pre-frontal cortex during language comprehension. NeuroImage, 49(1), 782-793.

Nelson-LeGall, S., \& Resnick, L. B. (1998). Help seeking, achievement motivation, and the social prac- tice of intelligence in school. In S. A. Karabenick (Ed.), Strategic help seeking: Implications for learning and teaching (pp. 39-60). Mahwah, NJ: Erlbaum.

O'Brien, E. J., Cook, A. E., \& Guéraud, S. (2010). Accessibility of outdated information. Journal of Experimental Psychology: Learning, Memory, $\mathcal{E}$ Cognition, 36(4), 979-991.

O'Reilly, T., \& McNamara, D. S. (2007). Reversing the reverse cohesion effect: Good texts can be better for strategic, high-knowledge readers. Discourse Processes, 43(2), 121-152.

Ozuru, Y., Best, R., Bell, C., Whiterspoon, A., \& McNamara, D. (2007). Influence of question format and text availability on the assessment of expository text comprehension. Cognition and Instruction, 25(4), 399-438.

Poyatos, F. (1977). Forms and functions of nonverbal communication in the novel: A new perspective of the author-character-reader relationship. Semiotica, 21(3-4), 295-338.

Radvansky, G. A., \& Copeland, D. E. (2010). Reading times and the detection of event shift processing. Journal of Experimental Psychology: Learning, Memory, and Cognition, 36(1), 210-216.

Raposo, A., Moss, H., Stamatakis, E. A., \& Tyler, L. K. (2009). Modulation of motor and premotor cortices by actions, action words, and action sentences. Neuropsychologia, 47(2), 388-396.

Rapp, D. N., Komeda, H., \& Hinze, S. R. (2011). Vivifications of literary investigation. Scientific Study of Literature, 1(1), 122-134.

Rueschemeyer, S. -A., Lindemann, O., van Rooj, D., van Dam, W., \& Bekkering, H. (2010). Effects of intentional motor actions on embodied language processing. Experimental Psychology, 57(4), 260-266.

Schafer, A. J., Speer, S., Warren, P., \& White, S. D. (2000). Intonational disambiguation in sentence production and comprehension. Journal of Psycholinguistic Research, 29(2), 169-182.

Schmitter-Edgecombe, M., \& Creamer, S. (2010). Assessment of strategic processing during narrative comprehension in individuals with mild cognitive impairment. Journal of the International Neuropsychological Society, 16(4), 661-671.

Siakaluk, P. D., Pexman, P. M., Sears, C. R., Wilson, K., Locheed, K., \& Owen, W. J. (2008). The benefits of 
sensorimotor knowledge: Body-object interaction facilitates semantic processing. Cognitive Science, 32(3), 591-605.

Simon, H. A. (1978). Information-processing theory of human problem solving. In W. K. Estes (Ed.), Handbook of learning and cognitive processes. $\mathrm{Hu}$ man information processing (Vol. 5, pp. 271-295). Hillsdale, NJ: Erlbaum.

Slepian, M. L., \& Ambady, N. (2012). Fluid movement and creativity. Journal of Experimental Psychology: General, 141(1), 625-629.

Speer, N. K., Reynolds, J. R., Swallow, K. M., \& Zacks, J. M. (2009). Readings stories activates neural representations of visual and motor experiences. Psychological Science, 20(8), 989-999.

Speer, S., \& Blodgett, A. (2006). Prosody. In M. Traxler \& M. A. Gernsbacher (Eds.), Handbook of psycholinguistics (2nd. ed., pp. 505-537). San Diego, CA: Academic Press.

Stanovich, K. E., \& Cunningham, A. E. (1991). Reading as constrained reasoning. In R. J. Sternberg \& P. A. Frensch (Eds.), Complex problem solving: Principles and mechanisms (pp. 3-60). Hillsdale, NJ: Lawrence Erlbaum Associates.

Suh, S., \& Trabasso, T. (1993). Inferences during reading: Converging evidence from discourse analysis, talk-aloud protocols, and recognition priming. Journal of Memory and Language, 32(3), 279-300.

Thomas, L. E., \& Lleras, A. (2009). Swinging into thought: Directed movement guides insight in problem solving. Psychonomic Bulletin Eु Review, 16(4), 719-723.

Trabasso, T., \& Sperry, L. L. (1985). Causal relatedness and importance of story events. Journal of Memory and Language, 24(5), 595-611.

Trabasso, T., \& van den Broek, P. (1985). Causal thinking and the representation of narrative events. Journal of Memory and Language, 24(5), 612-630.

Trabasso, T., van den Broek, P., \& Suh, S.Y. (1989). Logical necessity and transitivity of causal relations in stories. Discourse Processes, 12(1), 1-25.

Tulving, E. (1999). Episodic vs. semantic memory. In R. A. Wilson \& F. C. Keil (Eds.), The MIT encyclopedia of the cognitive sciences (pp. 278-280). Cambridge, MA: MIT Press.
Tzeng, Y., van den Broek, P., Kendeou, P., \& Lee, C. (2005). The computational implementation of the landscape model: Modeling inferential processes and memory representations of text comprehension. Behavior Research Methods, 37(2), 277-286.

van den Broek, P. (1990). The causal inference maker: Towards a process of inference generation in text comprehension. In D. A. Balota, G. B. Flores d'Arcais, \& K. Rayner (Eds.), Comprehension processes in reading (pp. 423-445). Hillsdale, NJ: Erlbaum.

van den Broek, P. (1994). Comprehension and memory of narrative texts: Inferences and coherence. In M. A. Gernsbacher (Ed.), Handbook of psycholinguistics (pp. 539-588). San Diego, CA: Academic Press.

van den Broek, P., \& Kendeou, P. (2008). Cognitive processes in comprehension of science texts: The role of co-activation in confronting misconceptions. Applied Cognitive Psychology, 22(3), 335-351.

van den Broek, P., Risden, K. C., \& Husebye-Hartmann, E. (1995). The role of readers' standards for coherence in the generation of inferences during reading. In R. F. Lorch \& E. J. O'Brien (Eds.), Sources of coherence in reading (pp. 353-373). Hillsdale, $\mathrm{NJ}$ : Lawrence Erlbaum.

van den Broek, P., \& Trabasso, T. (1986). Causal network versus goal hierarchies in summarizing text. Discourse Processes, 9(1), 1-15.

van Dijk, T. A., \& Kintsch, W. (1978). Cognitive psychology and discourse: Recalling and summarizing stories. In W. U. Dressler (Ed.), Current trends in text linguistics (pp. 61-80). New York: Aldine de Gruyter.

Versace, R., Labeye, E., Badard, G., \& Rose, M. (2009). The contents of long-term memory and the emergence of knowledge. European Journal of Cognitive Psychology, 21(4), 522-560.

Wang, Y., \& Chiew, V. (2010). On the cognitive process of human problem solving. Cognitive Systems Research, 11(1), 81-92.

Wiemer-Hastings, K., \& Xu, X. (2005). Content differences for abstract and concrete concepts. Cognitive Science, 29(5), 719-736.

Wojciehowski, H. C., \& Gallese, V. (2011). How stories make us feel. Toward an embodied narratology. California Italian Studies, 2 (1). Available at http:// escholarship.org/uc/item/3jg726c2 
Zacks, J. M., Speer, N. K., Swallow, K. M., \& Maley, C. J. (2010). The brain's cutting-room floor: Segmentation of narrative cinema. Frontiers in Human Neuroscience, 4(168). doi: 10.3389/fnhum.2010.00168

Zwaan, R. A., \& Rapp, D. N. (2006). Discourse comprehension. In M. Traxler \& M. A. Gernsbacher (Ed.), Handbook of psycholinguistics ( 2nd. ed., pp. 725-764). San Diego, CA: Academic Press.
Zwaan, R. A., \& Radvansky, G. A. (1998). Situation models in language and memory. Psychological Bulletin, 123(2), 162-185.

Zwaan, R. A., Graesser, A., \& Magliano, J. (1995). Dimensions of situation model construction in narrative comprehension. Journal of Experimental Psychology: Learning, Memory and Cognition, 21(2), 386-397. 
